Article

\title{
Accurate Characterization of Land Cover in Urban Environments: Determining the Importance of Including Obscured Impervious Surfaces in Urban Heat Island Models
}

\author{
Paul Coseo ${ }^{1, *}$ and Larissa Larsen ${ }^{2}$ \\ 1 The Design School, Arizona State University, Tempe, AZ 85287, USA \\ 2 Urban and Regional Planning, University of Michigan, Ann Arbor, MI 48109, USA; larissal@asu.edu \\ * Correspondence: Paul.Coseo@asu.edu; Tel.: +1-734-678-3964
}

Received: 30 April 2019; Accepted: 22 June 2019; Published: 25 June 2019

check for updates

\begin{abstract}
Urban heat islands (UHI) increase summer temperatures and can threaten human well-being during extreme heat events. Since urbanization plays a key role in UHI development, accurate quantification of land cover types is critical to their identification. This study examines how quantifying land cover types using both two- and three-dimensional approaches to land cover quantification affects an UHI model's explanatory power. Two-dimensional approaches treat tree canopies as a land cover, whereas three-dimensional approaches document the land cover areas obscured under tree canopies. We compare how accurately the two approaches explain elevated air temperatures in Chicago, Illinois. Our results show on average $14.1 \%$ of impervious surface areas went undocumented using a two-dimensional approach. The most common concealed impervious surfaces were sidewalks, driveways, and parking lots $(+6.2 \%)$, followed by roads $(+6.1 \%)$. Yet, the three-dimensional approach did not improve the explanatory power of a UHI model substantially. At 2 a.m., the adjusted $\mathrm{R}^{2}$ increased from 0.64 for a two-dimensional analysis to 0.68 for a three-dimensional analysis. We found that the less time consuming two-dimensional quantification of land covers was sufficient to predict neighborhood UHIs. As climate change exacerbates UHI, more cities will map urban hotspots and this research increases our understanding of alternative approaches.
\end{abstract}

Keywords: urban heat islands; land cover characterization; heat vulnerability; urban climate

\section{Introduction}

Past studies have linked urban land covers to urban heat islands (UHI) [1-4], particularly the presence of impervious surfaces and the absence of vegetation. UHIs refer to locally elevated air temperatures resulting from urban materials that increase absorption of solar radiation and change land cover's energy balance [1,5]. Although anthropogenic activities, geological patterns (e.g., mountains and water bodies), and weather patterns play a role in the formation of UHIs, understanding the contribution of urbanization is critical for planning and design of more thermally comfortable cities. High air temperatures negatively impact human health, air and water quality, urban soil quality and tree health, and infrastructure [2]. High air temperatures also indirectly increase waste heat emissions from increased air-conditioning, energy, and water use [1,6-9]. For the past decade, researchers, urban planners, designers, and decision-makers have sought to identify where UHIs exist in an effort to prioritize the location of heat mitigation interventions. A common approach to find where UHIs occur is to locate areas of high impervious surfaces. These impervious areas are used as an indicator for urban-induced heating. 
Impervious surfaces and their configuration are a key urban environmental indicator for a variety of weather hazards [10]. Impervious pavements and buildings make up a substantial percentage of land cover areas in U.S. cities. Large areas of impervious surfaces exacerbate several environmental problems including: (1) moisture deficits due to soil sealing and lack of vegetation; (2) stormwater flooding and reductions in water quality; and (3) more intense UHIs [1-3,11,12]. As the percentage of impervious surfaces increase in an area there is less planting area for healthy vegetation, which results in less moisture from plants and soils [11]. Warm pavements cause urban soils to dry more rapidly than rural soils not only putting further stress on plants but further exacerbating the dry urban climates [1]. Pavements seal off rainwater and air from entering or leaving soils. Ironically, this not only leads to flash flooding, but also restricts moisture in urban soils available for cooling. Rain falling on impervious pavements collects on the warm impervious surface instead of soaking into the soil. Collected run-off, warmed by urban surfaces, results in flooding and degradation of local streams and water bodies [13]. Finally, impervious materials change the reflectivity and energy balance of surfaces resulting in locally higher air temperatures or UHIs [1,2]. For this reason, vegetation and permeable soils play a critical role in moderating and dampening the warming effects of impervious land covers in urban environments. Imhoff and colleagues [3] found that the percentage of impervious surfaces explained $60 \%$ to $90 \%$ of the variance in land surface temperatures of 38 metro areas in North America, indicating its relative role in creating high land surface temperatures. However, it is more complicated when it comes to air temperatures. Zhang and colleagues [14] found that the percent impervious surfaces contributed to high air temperatures varied from day to night. They found the percent of impervious surfaces of 17 Detroit area sites explained $59 \%$ of the variance in average daily minimum air temperatures ( 5 a.m.), yet at 5 p.m. percent impervious surface was not a significant driver of local warming. They found that for every $10 \%$ increase in impervious surface area, average minimum temperatures at $5 \mathrm{a} . \mathrm{m}$. were $0.40{ }^{\circ} \mathrm{C}$ warmer [14]. Yet, it is not just the land cover composition of impervious surfaces that play a key role, it is also the three-dimensional configuration as well.

Several authors have examined the role land cover spatial arrangement or configuration plays on energy balance. Parcel size [15], compactness [16], and continuity [17] of the urban development have all been found to influence thermal patterns. A study of Atlanta used NASA thermal imagery to examine the thermal fluxes associated with parcel size, a proxy for land cover configuration. Stone and Rodgers [15] found that on average, for every quarter acre increase in parcel size, there was a 33\% increase in net thermal emissions when compared to a native pine forest landscape. Northern Georgia's pine forests highly regulate thermal emissions and by replacing those forests with lawns, thermal emissions increase substantially. Thus, using this method Stone and Rodgers concluded that more compact, smaller parcels contributed less to lower atmospheric heating in this bioclimatic region than larger lot residential. However, Coutts, Beringer, and Tapper [16], examining Melbourne's heat fluxes, showed the dynamics of the surface energy balance in low, medium, and high compact neighborhoods interacted with design choices on albedo, vegetation types, irrigation practices, and anthropogenic heat emissions that complicated local-scale fluxes. They found that the ratio of latent heat flux to total net radiation was higher in a high compact neighborhood with lower vegetation density than a medium compact neighborhood and that it was likely due to irrigation practices and vegetation type differences between the two neighborhoods. Urban neighborhood's composition and configuration of impervious surfaces are key environmental indicators for UHIs and other environmental hazards; therefore, research indicates the importance of accurately identifying these surfaces in three-dimensions for UHI research.

Many researchers rely on overhead aerial images to characterize land cover. Overhead images simplify the urban environment into two dimensions and therefore can obscure land cover underneath tree canopies, structural shade canopies, and roof overhangs. Omitting impervious surfaces may have significant impacts on the study outcomes. Akbari and colleagues [18] developed a more accurate, three-dimensional approach, that documents land cover beneath trees and elevated structures. They found that the three-dimensional approach increased the documented impervious from a 
two-dimensional estimate of $64 \%$ coverage to a more accurate impervious surfaces coverage of $81.6 \%$. The added $17.6 \%$ of impervious surface was hidden beneath downtown Sacramento, CA's tree canopy [18]. Although Akbari and colleagues [18] were not investigating urban heat islands, the study has potentially significant implications for UHI research. This implies that in many cities, large areas of impervious surface go undocumented. Determining the amount of impervious area obscured by vegetation and/or overhead structures adds an additional step in the analysis process. However, the three-dimensional approach could help address Stewart's [5] call to urban climatologists to create more accurate descriptions of urban areas' physical characteristics for urban heat island modeling. To the best of our knowledge, no past research has investigated whether this additional impervious area significantly alters the accuracy of UHI models.

This study compares a two-dimensional characterization of land cover to a three-dimensional approach to determine whether calculating the area of obscured impervious surface significantly improves our ability to predict air temperature. The study is structured around two research questions. First, what is the difference between two-dimensional and three-dimensional characterization of impervious surfaces in eight Chicago neighborhoods? We anticipate that using a more accurate three-dimensional approach to account for the impervious surfaces will increase the accuracy of land cover characterization in the eight neighborhoods. Next, how does accounting for impervious surfaces under tree canopies with the three-dimensional approach improve the UHI model's explanatory power? We expect that more accurate three-dimensional calculations of impervious surface area will substantially improve the UHI models explanatory power. We use orthoimagery from April 2010 to quantify and compare two- and three-dimensional calculations of land cover on eight Chicago neighborhood blocks. We then combine this data with air temperatures collected during July and August 2010 to understand the impacts on air temperature. This article begins with a literature review of urban-induced warming and then links this to how previous studies have measured land cover. We then describe the experiment, report the findings, and discuss the implications of the trade-offs between the two approaches to calculating impervious surfaces and if that additional information significantly improves a UHI model's explanatory power.

\section{Previous Urban Heat Island and Land Cover Research}

UHI research and analysis requires precise measurements of land cover types to understand the relationship between urban materials and UHIs. Pauleit and Duhme [19] suggest that many calculations of urban land cover are "misleading" for many cities and that more accurate accounting of land cover is necessary for planning and design purposes. In this section, we discuss (1) how land cover type drives urban-induced warming, (2) how land cover is measured, and (3) approaches to characterizing land cover in urban environments.

Land cover types drive urban-induced warming, so accurately depicting those land covers should improve UHI model's explanatory power. Cities are typically warmer than adjacent rural locations as a consequence of converting natural land cover types to urban types. Urban land cover types have impervious pavements and three-dimensional buildings made from artificial materials such as concrete, asphalt, masonry, and metals. These building materials increase local air temperatures by altering the reflectivity (albedo), energy balance (emissivity), and permeability of natural land covers.

Urban impervious land cover exposed to full solar radiation absorbs and stores more incoming shortwave radiation compared with vegetated areas and shaded impervious surface areas. Dark ground surfaces such as new asphalt reflect only $5 \%$ of incoming solar radiation, while absorbing the remaining 95\% [20]. Synnefa and colleagues [21] found that the surface temperature of standard black tiled roof in Athens, Greece was as much as $10.2^{\circ} \mathrm{C}$ warmer relative to a highly reflective tiled roof. In addition, urban land cover alters the energy balance of the land. Once incoming solar radiation is absorbed by urban materials, it is converted to stored heat energy. Asphalt and concrete pavements have high emissivity values over 0.90, effectively storing and re-emitting energy (asphalt, 0.95-0.971; concrete, $0.90-0.98$ ) [22], heating the atmosphere in contact with those materials. Impervious surfaces 
reduce the available area for planting vegetation and seal soils. Therefore, sealing soils limits the exchange of moisture from the soil to the lower atmosphere. Local moisture is important because once heat energy is emitted from urban materials it is released as 1) sensible heat energy, 2) longwave radiation, and 3) latent heat energy [1,2]. Both sensible heat and longwave radiation contribute to UHIs [1] while latent heat energy is dependent on the presence of local moisture and thus does not contribute to UHIs. Latent heat energy is due to evaporation, which acts as a cooling process [1].

Vegetated land cover is an important source of evapotranspiration and shade. When the climate regulating aspects of vegetation are replaced with urban materials, warming occurs. Imhoff and colleagues [3] examined eight U.S. bioregions and found that the most intense UHIs $\left(8^{\circ} \mathrm{C}\right)$ were in regions where forest canopies helped moderate air temperatures through evapotranspiration. The removal of forest and the construction of urban impervious surfaces increased the intensity of UHIs in these regions. Vegetated ground covers such as turf grass lawns reflect $16 \%$ to $26 \%$ of incoming light [23] and provide cooling evapotranspiration, yet turf grass does not provide the same scattering of light or shade as tree canopies.

Trees' elevated canopies help control local air temperatures during the night and day. During the night, studies have found that reduced sky view factor from trees reduces the escape of longwave radiation and inhibits efficient radiational cooling [24,25]. However, Coutts and colleagues [24] examining three east-west street canyons in Melbourne, Australia found that at night buildings in a compact street canyon likely reduce the loss of longwave radiation to a greater extent than street trees in a shallow street canyon due to the porosity of trees. They suggest that although trees reduce the loss of longwave radiation at night, that should not deter cities from planting trees for their overall diurnal cooling benefits. They recommend strategic placement of trees to allow more ventilation and longwave radiation loss at night, while providing critical shade to sun exposed surface during the day.

During the day, tree leaves reflect, absorb, and scatter incoming sunlight, transmitting a percentage of the total shortwave radiation. Thus, trees are a key urban element that shades urban surfaces from full exposure to solar radiation that ground vegetation does not provide. Most Midwestern trees reflect between $22 \%$ and $31 \%$ of incoming light (Table 1). Although some tree canopies have similar reflectance values as urban materials such as asphalt and concrete, trees provide other qualities that reduce the absorption and storage of heat energy such as transpiration. Trees do not absorb all non-reflected light [26]. Most tree species only absorb approximately 50\% of the incoming shortwave radiation. The remaining $20 \%-30 \%$ of the total incoming solar radiation reaches the ground below, passing through the tree canopy as transmitted light [26]. Transmissivity is the term used to describe the amount of direct and diffuse shortwave that passes through a material, in this case a tree's canopy. It is often presented as a percentage of the total shortwave radiation. Konarska and colleagues [27] measured the transmissivity of five temperate street tree species in Göteborg, Sweden. They showed the impact of tree species' leaf size, canopy structure, and other physical attributes of tree species and how species type affects the amount of radiation that reach ground level. They found that small-leaved linden's (Tilia cordata) shade is fairly dense with only $8.8 \%$ of possible shortwave radiation measured under its canopy [27]. Even with this evidence, there remains a lack of understanding of the relative impact of that transmitted shortwave radiation hitting impervious surfaces and the implications for UHI. In many cases, this may be because researchers have overlooked impervious surfaces under tree canopy when classifying land cover types.

Aerial images permit researchers to classify land cover over large spatial areas. All aerial images are composed of a series of pixels. The pixel resolution represents the smallest unique unit area that is discernible in a raster image. The pixel resolution of the images may vary from one pixel representing a 2700 meter $^{2}\left(29,603 \mathrm{ft}^{2}\right)$ area (Operational Linescan System or O.L.S) to one pixel representing a 0.30 meter $^{2}\left(3.2 \mathrm{ft}^{2}\right)$ area (orthoimagery) depending on whether they are from high altitude flights, satellites, or near-earth aerials [18,28-31]. 
Table 1. Table of typical reflection, absorption, and transmission of shortwave radiation by common street trees in the Chicago region-adapted from [26] (p. 227). *

\begin{tabular}{llccc}
\hline \multicolumn{1}{c}{ Common Name } & \multicolumn{1}{c}{ Genus Species } & \% Reflectance & \% Absorption & \% Transmission \\
\hline Green Ash & Fraxinus Pennsylvanica & 31 & 51 & 18 \\
Cottonwood & Populus Deltoides & 24 & 50 & 26 \\
Silver Maple & Acer Saccharinum & 23 & 48 & 29 \\
Tulip Tree & Liriodendron Tulipifera & 24 & 52 & 24 \\
White Oak & Quercus Alba & 22 & 44 & 34 \\
\hline
\end{tabular}

${ }^{*}$ Reflectance + Absorption + Transmission $=100 \%$ of incoming solar radiation.

As a result of the raster format of the images, researchers select either a 1) pixel or 2) object-oriented classification technique to characterize different land cover types from aerial images [32]. A pixel-oriented technique relies on the resolution of the image pixels to classify land cover types. Therefore, a pixel-oriented technique does not match land cover types with meaningful objects such as parcels, buildings, or rights-of-ways [32]. This approach results in a coarse analysis that is less appropriate for planning urban rights-of-way and urban forests.

The object-oriented technique is an effort to overcome this limitation. An object-oriented technique classifies land cover types by classifying land segments (areas) as opposed to pixels [32]. Geneletti and Gorte write, [32] (p. 1274) ... "[t]he term segment refers to a cluster of adjacent pixels that represents a meaningful object on the terrain, from the user point of view". Parcels, buildings, pavement, and other objects are more useful for planning purposes than are pixels. Geneletti and Gorte [32] proposed an object-oriented technique using both high- and low-resolution images to classify land cover types. They found using both high and low-resolution images in Trento, Italy that they were able to improve the accuracy and reliability of land cover classification by around $2 \%$ over using the low-resolution Landsat TM alone [32]. Although it did not improve the accuracy by much, they found that using object-oriented technique with the higher resolution orthoimagery $(7.5 \mathrm{~m})$ resulted in clearer and better delineation between land covers than using the pixel-oriented technique with the Landsat TM (30 m) [32].

Examining land cover in Guangzhou, China, Guo and colleagues [33] found that an object-oriented approach combined with land cover indices of normalized differential vegetation index (NDVI) and normalized differential build-up index (NDBI) was useful to identify UHI clusters from land surface temperatures (LST). They found that NDVI had a -0.67 ( $\mathrm{p}<0.05$ level) Pearson correlation with LST, while NDBI had a +0.66 ( $p<0.05$ level). Their method was developed as a way to create a more meaningful approach for urban planning decision-making and practice. This object-oriented technique is more useful since analysis of land cover is usually followed up by recommendations for changes to parcels, rights-of-way, pavements, and buildings on the ground. In particular, state and local departments of transportation are often responsible for rights-of-way planning. An accurate account of sidewalk, street, and pervious areas within the rights-of-way is necessary for design purposes. In addition, urban foresters require accurate information of ground level pervious areas available for planting of shade trees. Only certain species of trees are able to survive planting in tree pits.

Researchers use ground surveys, two-dimensional approaches, and three-dimensional approaches to characterize land covers in urban environments. Table 2 is a list of past research describing the type of aerial image data used, its resolution, and general approach. A fine-grained approach is based on ground surveys of small areas or a few samples. At a very fine scale some researchers use ground surveys to document land cover classes [32,34,35]. Again, the limitation here is that the scale of analysis is quite small. Several researchers have used ground surveying in combination with aerial or satellite data to ground truth a few samples of land cover types [32,34]. This approach is problematic when covering large spatial extents and may need to be repeated regularly to address changes in neighborhood land cover. 
Table 2. Approach to quantifying land cover types by author.

\begin{tabular}{|c|c|c|c|c|c|c|}
\hline Authors & City or Region & Type of Image & Pixel Resolution (m) & Ground Survey & Two-Dimensional & Three-Dimensional \\
\hline Akbari et al., 2003 [18] & Sacramento, CA & Orthoimagery & 0.3 & & & $\mathrm{x}$ \\
\hline Akbari and Rose, 2001 [29] & Chicago, IL & Orthoimagery & 0.3 & & & $x$ \\
\hline Akbari and Rose, 2001[30] & Salt Lake City, UT & Orthoimagery & 0.3 & & & $x$ \\
\hline Chang et al., 2007 [34] & Taipei City, Taiwan & Ground survey and aerials & $\mathrm{NS}^{*}$ & $\mathrm{x}$ & & $\mathrm{x}$ \\
\hline Chen et al., 2006 [38] & Pearl River Delta, China & IKONOS 2000 & 4 & & $\mathrm{x}$ & \\
\hline Geneletti and Gorte, 2003 [32] & Trento, Italy & Landsat TM and Orthoimagery & (Landsat), 7.5 m (Ortho) & $\mathrm{x}$ & $\mathrm{x}$ & $\mathrm{x}$ \\
\hline Gill et al., 2008 [39] & Manchester, England & "Cities Revealed" Aerial & 0.25 & & $\mathrm{x}$ & \\
\hline Gray and Finster, $2000[40]$ & Chicago, IL & Orthoimagery & 0.3 & & $\mathrm{x}$ & \\
\hline Imhoff et al., 2010 [3] & 38 Bioregions & Landsat 7 ETM+ and IKONOS & 30 (Landsat), 4(IKONOS) & & $\mathrm{x}$ & \\
\hline Li and Weng, 2007 [41] & Indianapolis, IN & Landsat 7 ETM+ & $\mathrm{NS}^{*}$ & & & \\
\hline Liang and Weng, 2011 [42] & Indianapolis, IN & Landsat $7 \mathrm{TM}$ and ETM+ & $\mathrm{NS}^{*}$ & & & \\
\hline Matsuoka et al., 2007 [28] & Yellow River, China & MODIS and OLS & 250 (MODIS), 2,700 (OLS) & & & \\
\hline McPherson et al., 1994 [43] & Chicago, IL & Satellite and Aerials & $\mathrm{NS}^{*}$ & $\mathrm{x}$ & & $\mathrm{x}$ \\
\hline Nichol and Wong, 2005 [37] & Hong Kong & IKONOS & 4 & & & $\mathrm{x}$ \\
\hline Nowak and Greenfield, 2012 [44] & 20 U.S. Cities & Aerials & $0.15-2$ & & $x$ & \\
\hline Nowak et al., 1996 [45] & 58 U.S. Cities & Aerials & $\mathrm{NS}^{*}$ & & $\mathrm{x}$ & \\
\hline Rose et al., 2003 [31] & Houston, TX & Orthoimagery & 0.3 & & & $\mathrm{x}$ \\
\hline Solecki et al., 2005 [36] & Newark and & Aerials & $\mathrm{NS}^{*}$ & & $\mathrm{x}$ & \\
\hline Yuan and Bauer, 2007 [46] & Minneapolis, MN & $\begin{array}{l}\text { Landsat } 5 \text { TM, Landsat } 7 \text { ETM+, } \\
\text { and Orthoimagery }\end{array}$ & $\begin{array}{l}120 \text { (Landsat 5), } 60 \\
\text { (Landsat 7), } 1 \text { (Ortho) }\end{array}$ & & $x$ & \\
\hline
\end{tabular}

* Not Specified, IKONOS—is derived from the Greek word for image, MODIS-Moderate Resolution Imaging Spectroradiometer, OLS—Operational Linescan System. 
The two-dimensional approach is the most commonly used analysis type and offers the benefit of using coarse or fine resolution image data to analyze large spatial areas. Yet, two-dimensional approaches do not generally differentiate between types or levels of vegetation. Tree canopy is usually not distinguished from ground level vegetation and land cover beneath tree canopy is not documented. Solecki and colleagues [36] used a finer scale two-dimensional approach to calculate land cover variables for six single urban blocks in Newark and Camden, New Jersey. Using a two-dimensional approach, they found tree canopy cover in the six neighborhoods varied from $10 \%$ to $26 \%$, while paved surfaces varied from $18 \%$ to $30 \%$ and roof surfaces varied from $19 \%$ to $44 \%$ [36]. However, it is not known how much impervious roof and paved areas went undocumented, especially in neighborhoods with single storied buildings and tree canopy. In medium- to high-density neighborhoods with moderate to high percentages of tree canopy, substantial areas of impervious surface under tree canopies are missed by using a two-dimensional approach (Figure 1). A more accurate three-dimensional approach is much less commonly used but could help to more accurately account for land covers under tree canopies.

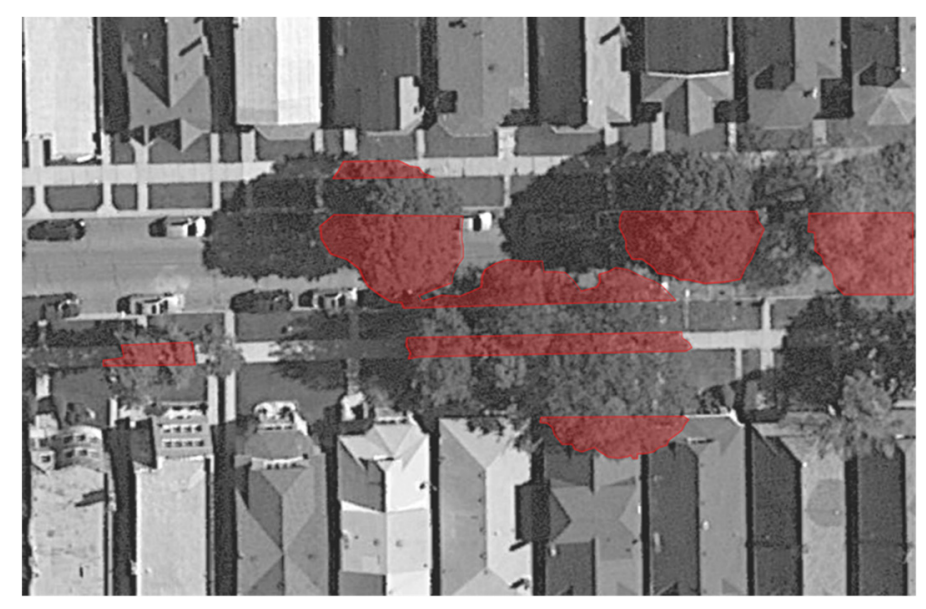

Figure 1. Graphic depicting areas of impervious pavement, sidewalk, and roof surfaces concealed by tree canopy. The areas shaded in red go undocumented by two-dimensional approach. Not to scale, for illustration only. Source: Google Earth, 2019. Illustration: by authors.

A three-dimensional approach attempts to accurately quantify ground level, multiple roof levels, tree canopy level, and in some cases building wall areas [18,31,37]. To date, most three-dimensional analysis has been at fine scales using aerial images less than four meters [37]. Most of the research comes out of the Lawrence Berkeley National Laboratory's Heat Island Group examination of Sacramento, Chicago, Salt Lake City, and Houston [18,29-31] provided guidance to sample smaller areas and extrapolate to urban landscapes with similar physical characteristics. Akbari and colleagues [18] developed a multi-step land cover classification for areas with fairly homogenous land cover composition. The method involved: 1) visually inspecting the variety of surface-types of 0.3 meter pixel aerial orthoimagery; 2) grouping those surface-types into broad surface-type categories; 3 ) employing an automated Monte Carlo approach to randomly sample a subset of the pixel data, visually inspect those samples, and then assign surface-type to the pixels; and 4) extrapolate those findings to larger spatial areas such as metropolitan regions. They found the accuracy of land cover classification improved significantly using this three-dimensional approach [18]. Akbari and colleagues [18] found that documenting the impervious surface areas beneath tree canopy raised impervious surface counts from $64 \%$ to $81.6 \%$ in downtown Sacramento, CA. Rose and colleagues [31] found that once impervious surfaces under the tree canopy were quantified that downtown Houston had $58 \%$ paved surfaces and 34\% roofed surfaces. A similar analysis by Akbari and Rose [29] found that the most commonly missed surfaces using a two-dimensional approach in three medium-density Chicago neighborhoods (Wrigleville, Lincoln Park, and Rodgers Park) were grass areas, road, parking lots, and sidewalks. Roof surface calculations were not as affected by the type of approach. Roof surfaces were nearly identical 
in both approaches; trees did not provide a significant amount of concealment of roof surfaces [29]. Akbari and Rose [29] argue that these more accurate measurements are necessary for city officials to make better decisions for UHI mitigation planning and design purposes. While more accurate information will certainly help with more targeted planning and design decisions, what is missing from the research to date is a rigorous assessment of whether using these more accurate approaches to calculating land cover improves our understanding of UHIs.

\section{Experiments}

The Chicago-Joliet-Naperville metropolitan statistical area is an urbanizing area with a 2010 population of 9,461,105. Up 4\% from 2000 [47], most of this growth is taking place at the rural fringe of the metropolitan area. The region lies on the flat Lake Michigan coastal plain (41 $52^{\prime} 55^{\prime \prime}$ North and $087^{\circ} 37^{\prime} 40^{\prime \prime}$ West [48]) with an average elevation of $190.80 \mathrm{~m}$ above sea level (ranging $176.5 \mathrm{~m}$ to $205.1 \mathrm{~m})$ [49]. The average mean temperature from May to September is $25.9^{\circ} \mathrm{C}(1961-1990)$ [50]. Since the 1995 Chicago heat wave, when up to 800 perished due to the heat [51,52], the City of Chicago has worked with researchers and sought policies to document the urban heat island drivers and address heat vulnerability $[4,40,53,54]$. Thus, Chicago has been a leader in bridging research and policy on urban-induced heating. The City of Chicago was chosen for this study because of this leadership in heat mitigation and to continue this linking of research to understand UHI with heat mitigation policy. The city helped facilitate permissions for the deployment of weather stations, which can be hard to accomplish without city cooperation. This research was a part of a larger partnership with the Chicago Department of Transportation to help evaluate Chicago's heat mitigation.

Historically, a mixture of prairie and temperate forest land covers played an important role in moderating air temperatures. Urbanization over the last two centuries has transformed those prairie covers to impervious covers while also increasing regional tree coverage from a pre-settlement estimate of $13 \%$ to $20 \%$ as of the mid 1990s [55]. However, in the city of Chicago, tree canopy covers only $11 \%$ of the land area on average, which is slightly lower than pre-settlement conditions [55]. Using a two-dimensional approach, Nowak and Greenfield [44] found that the Chicago region's 2009 tree and shrub coverage $(18 \%)$ was less than the average of $28.2 \%$ for the 20 U.S. cities they studied (Table 3). They also found that Chicago, like other cities in the study, had lost tree canopy within the five year period. Between 2005 to 2009 , the tree canopy declined by $0.5 \%$. This decline is similar to declines in urban vegetative cover in other north central U.S. cities (Detroit, $-0.7 \%$, Minneapolis, $-1.1 \%$, Kansas City, $-1.2 \%$ ) [44]. During the same period, reported impervious covers remained largely unchanged in the Chicago region. Furthermore, using a two-dimensional approach, a more detailed land cover analysis in 2000 of 14 Chicago neighborhoods by Gray and Finster [40] found that roofs constituted $29.8 \%$ to $36.9 \%$ of land cover types while pavement made up $18.3 \%$ to $25.6 \%$ of the land cover types. Although, it is unknown how much impervious surfaces might have gone undocumented from these studies. This is because in compact urban neighborhoods tree canopy coverage is not necessarily determined by the amount of pervious planting areas due to trees planted in tree pits and thus impervious to pervious coverage varies greatly within the City.

Using a three-dimensional approach, Akbari and Rose [29] found that tree canopy in mediumto high-density Chicago neighborhoods varied from as low as 3.7\% in Pilsen with $71.3 \%$ impervious surface areas to as much as $13 \%$ in Wrigleyville with a similar (75.6\%) amount of impervious surfaces (Table 4). While Akbari and Rose [29] used the same orthoimagery data as Gray and Finster [40], they used a three-dimensional approach and found that impervious surfaces varied between different medium- to high-density Chicago neighborhoods. Roofs covered from a low of $19.2 \%$ of surfaces in Garfield Park to as much as 34.4\% in Pilsen [29]. They found that roads covered from $12.4 \%$ of surfaces in Rodgers Park to as much as $23.3 \%$ of surfaces in Wrigleville. Yet, they counted alleys within their miscellaneous category and thus fairly large areas of impervious pavement are not accurately accounted for in the pavement numbers. According to the Chicago Department of Transportation, alley public rights-of-way constitute about $2.4 \%$ of all land in the City or 3500 acres [56]. All pavements 
covered between $23.3 \%$ of surfaces in Rodgers Park to as much as $32.9 \%$ in Wrigleville [29]. Although it is useful for city officials to have more accurate accounts of land cover types for planning and design purposes, how do these more accurate representations of the urban environment impact predictions of UHI?

For this study, we selected eight neighborhood cases (Figure 2) using ESRI ArcGIS based on three criteria as detailed in [4]. The selection criteria were based on a neighborhood's 1) likelihood of developing UHIs, 2) income levels, and 3) demographic variation. We then selected one representative block within those eight neighborhoods for analysis. Table 5 and 6 describe the eight selected blocks' land cover and other physical properties including differences between two- and three-dimensional approaches. Most of the case blocks are comparable in size. However, the Bronzeville block was a long north-south block roughly double the size of the other blocks at 40,162 $\mathrm{m}^{2}\left(432,300 \mathrm{ft}^{2}\right)$. The neighborhood with the most impervious surface (including impervious surface under tree canopies) was Wicker Park. Both the Wicker Park and Little Italy blocks were approximately 95\% impervious. Beverly had the lowest number of impervious surfaces with less than $55 \%$ impervious surface. Wicker Park had the lowest amount of tree canopy (4.8\%), while Beverly had the most tree canopy $(60 \%)$. Only eight neighborhoods were selected due to constrained resources and the difficulty of receiving approvals from the City of Chicago and local utilities to site weather stations.

Table 3. Two-dimensional approach to quantifying urban land cover change for 20 U.S. cities* compared to Chicago from Reference [44].

\begin{tabular}{|c|c|c|c|c|}
\hline Land Cover Type & $\begin{array}{c}\text { Average \% for } 20 \\
\text { Cities* in } 2009\end{array}$ & $\begin{array}{l}\text { Average \% for } \\
\text { Chicago in } 2009\end{array}$ & $\begin{array}{c}\text { Change in \% } \\
\text { Between } 2005 \text { and } \\
2009 \text { for } 20 \text { Cities }\end{array}$ & $\begin{array}{c}\text { Change in \% } \\
\text { Between } 2005 \text { and } \\
2009 \text { for Chicago }\end{array}$ \\
\hline Grass/Herbaceous Cover & $24.7 \%$ & $20.7 \%$ & 0.5 & -0.1 \\
\hline Tree/Shrub Cover & $28.2 \%$ & $18.0 \%$ & -1.5 & -0.5 \\
\hline Impervious Buildings & $15.9 \%$ & $26.8 \%$ & 0.3 & -0.3 \\
\hline Impervious Roads & $12.3 \%$ & $12.1 \%$ & 0.3 & 0.0 \\
\hline Impervious Other & $14.8 \%$ & $19.6 \%$ & 0.8 & 0.3 \\
\hline Water & $0.1 \%$ & $0.2 \%$ & 0.1 & 0.2 \\
\hline Bare Soil & $4.0 \%$ & $2.6 \%$ & -0.3 & 0.4 \\
\hline Total & $100 \%$ & $100 \%$ & & \\
\hline \multicolumn{2}{|c|}{$\begin{array}{c}\text { *20 cities included in the study: } \\
\text { Albuquerque, NM } \\
\text { Atlanta, GA } \\
\text { Baltimore, MD } \\
\text { Boston, MA }\end{array}$} & $\begin{array}{c}\text { Chicago, IL } \\
\text { Denver, CO } \\
\text { Detroit, MI } \\
\text { Houston, TX } \\
\text { Kansas City, MO } \\
\text { Los Angeles, CA }\end{array}$ & $\begin{array}{c}\text { Miami, FL } \\
\text { Minneapolis, MN } \\
\text { Nashville, TN } \\
\text { New Orleans, LA } \\
\text { New York, NY }\end{array}$ & $\begin{array}{l}\text { Pittsburgh, PA } \\
\text { Portland, OR } \\
\text { Spokane, WA } \\
\text { Syracuse, NY } \\
\text { Tacoma, WA }\end{array}$ \\
\hline
\end{tabular}


Table 4. Two and three-dimensional orthoimagery land cover analysis of five medium density Chicago neighborhoods in 2000 from Reference [29].

\begin{tabular}{|c|c|c|c|c|c|c|c|c|c|c|c|c|c|c|c|c|c|c|c|}
\hline \multicolumn{20}{|c|}{ Impervious Cover-type (Percent of Total Cover) } \\
\hline & \multicolumn{3}{|c|}{$\begin{array}{l}\text { Total Impervious } \\
\text { Surface Area * }\end{array}$} & \multicolumn{3}{|c|}{ Roof } & \multicolumn{3}{|c|}{ Road } & \multicolumn{3}{|c|}{ Parking Area } & \multicolumn{3}{|c|}{ Sidewalk/Driveway } & \multirow{2}{*}{$\begin{array}{c}\text { Private Paved } \\
\text { Surfaces (2-D Not } \\
\text { Calculated) }\end{array}$} & \multicolumn{3}{|c|}{ Miscellaneous } \\
\hline & 2-D & 3-D & $(\% \Delta)$ & 2-D & 3-D & $(\% \Delta)$ & 2-D & 3-D & $(\% \Delta)$ & 2-D & 3-D & $(\% \Delta)$ & 2-D & 3-D & $(\% \Delta)$ & & 2-D & 3-D & $(\% \Delta)$ \\
\hline Garfield Park & 50.3 & 52.9 & $(+2.6)$ & 19.2 & 19.2 & $(+0.0)$ & 13.8 & 15.0 & $(+1.2)$ & 3.7 & 3.7 & $(+0.0)$ & 7.1 & 7.1 & $(+0.0)$ & 3.1 & 6.5 & 4.8 & $(-1.7)$ \\
\hline Lincoln Park & 61.9 & 69.4 & $(+7.5)$ & 33.8 & 33.8 & $(+0.0)$ & 17.4 & 18.5 & $(+1.1)$ & 3.6 & 4.3 & $(+0.7)$ & 4.6 & 4.6 & $(+0.0)$ & 0.0 & 2.5 & 8.2 & $(+5.7)$ \\
\hline Pilsen & 69.3 & 71.3 & $(+2)$ & 34.4 & 34.4 & $(+0.0)$ & 22.1 & 22.3 & $(+0.2)$ & 3.7 & 4.0 & $(+0.3)$ & 7.7 & 7.7 & $(+0.0)$ & 0.3 & 1.4 & 2.6 & $(+1.2)$ \\
\hline Rodgers Park & 50 & 52.5 & $(+2.5)$ & 28.2 & 28.2 & $(+0.0)$ & 11.7 & 12.4 & $(+0.7)$ & 5.2 & 5.4 & $(+0.2)$ & 3.6 & 4.7 & $(+1.1)$ & 0.8 & 1.3 & 0.5 & $(-0.8)$ \\
\hline \multirow[t]{3}{*}{ Wrigleyville } & 65 & 75.6 & $(+10.6)$ & 32.4 & 32.4 & $(+0.0)$ & 20.3 & 23.3 & $(+3.0)$ & 4.2 & 4.2 & $(+0.0)$ & 4.8 & 4.8 & $(+0.0)$ & 0.6 & 3.3 & 10.6 & $(+7.3)$ \\
\hline & \multicolumn{6}{|c|}{ Total Pervious Surface Area ** } & \multicolumn{3}{|c|}{ Tree Cover } & \multicolumn{6}{|c|}{ Grass } & \multicolumn{4}{|c|}{ Barren Land } \\
\hline & \multicolumn{3}{|c|}{ 2-D } & \multicolumn{2}{|c|}{ 3-D } & $(\% \Delta)$ & \multicolumn{3}{|c|}{ 2-D } & \multicolumn{3}{|c|}{ 2-D } & 3-D & \multicolumn{2}{|c|}{$(\% \Delta)$} & 2-D & \multicolumn{2}{|c|}{ 3-D } & $(\% \Delta)$ \\
\hline Garfield Park & \multicolumn{3}{|c|}{49.7} & \multicolumn{2}{|c|}{47.2} & $(-2.5)$ & \multicolumn{3}{|c|}{5.9} & \multicolumn{3}{|c|}{35.3} & 38.7 & \multicolumn{2}{|c|}{$(+3.4)$} & 8.5 & \multicolumn{2}{|c|}{8.5} & $(+0.0)$ \\
\hline Lincoln Park & \multirow{2}{*}{\multicolumn{3}{|c|}{$\begin{array}{c}38 \\
30.6\end{array}$}} & \multirow{2}{*}{\multicolumn{2}{|c|}{$\begin{array}{l}30.6 \\
28.6\end{array}$}} & $(-7.4)$ & \multirow{2}{*}{\multicolumn{3}{|c|}{$\begin{array}{l}8.5 \\
3.7\end{array}$}} & \multirow{2}{*}{\multicolumn{3}{|c|}{29.5}} & 30.6 & \multicolumn{2}{|c|}{$(+1.1)$} & 0.0 & \multicolumn{2}{|c|}{0.0} & $(+0.0)$ \\
\hline Pilsen & & & & & & $(-2)$ & & & & & & & 26.9 & & $.7)$ & 1.7 & & 7 & $(+0.0)$ \\
\hline Rodgers Park & \multicolumn{3}{|c|}{49.9} & & & $(-2)$ & & 9.8 & & & 37.8 & & 45.1 & & .3) & 2.3 & & 8 & $(+0.5)$ \\
\hline Wrigleyville & & 34.8 & & & & $(-10.9)$ & & 13.0 & & & 21.2 & & 23.3 & & $.1)$ & 0.6 & & 6 & $(+0.0)$ \\
\hline
\end{tabular}

* Total Impervious Surface Area = Roof + Road + Parking Area + Sidewalk/Driveway + Private Surfaces + Miscellaneous (Misc. surfaces are defined by Akbari and Rose (2001:8) as “... the total of sporadic surface-types such as swimming pools, water, alleys, autos, private surfaces, and train tracks"). ${ }^{* *}$ Total Pervious Surface Area $=$ Grass + Barren Land. 


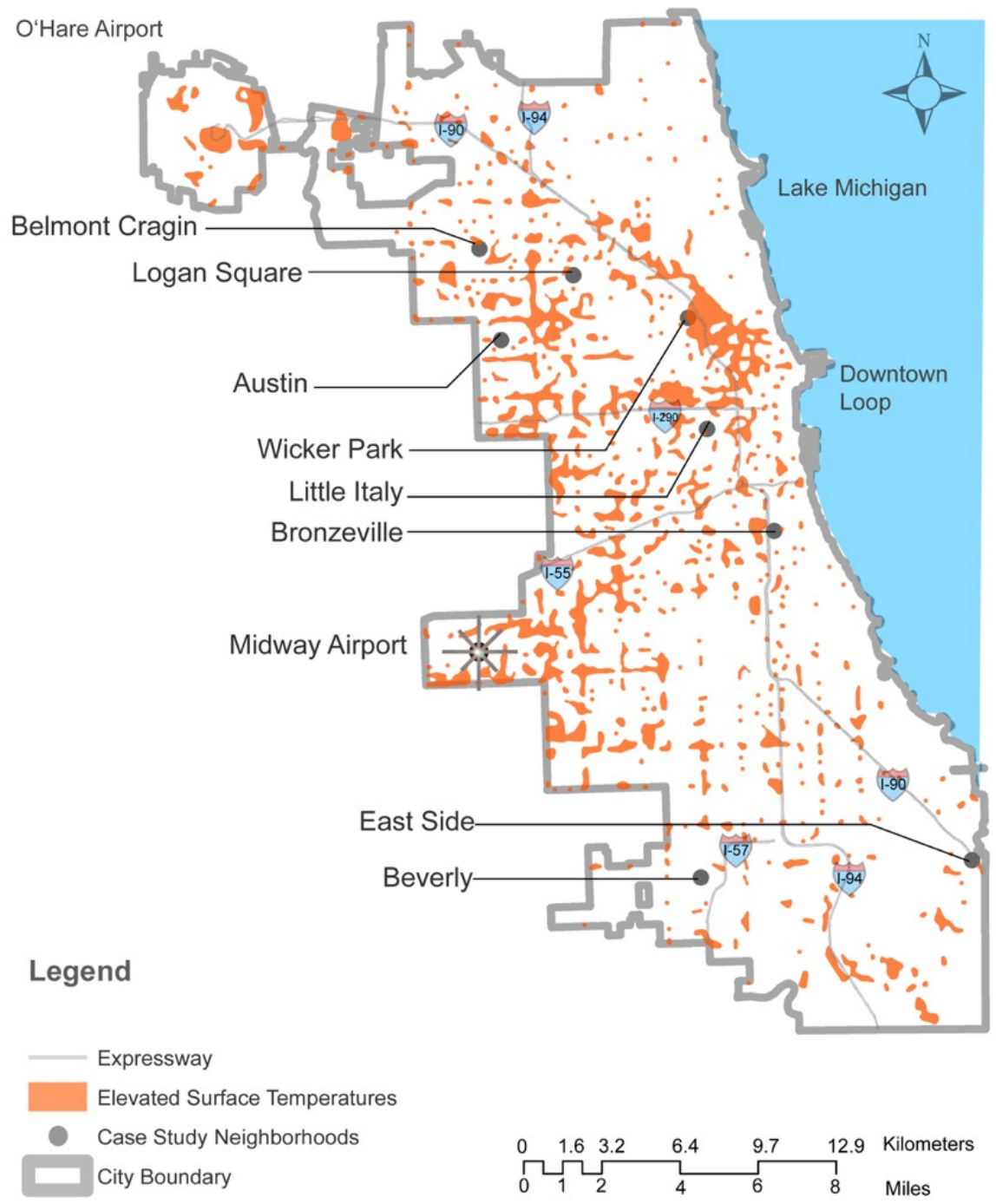

Figure 2. Map illustrating the city of Chicago limits, the eight study neighborhoods, Midway Airport, and the heterogeneous distribution of elevated surface temperatures from a City of Chicago Department of the Environment 2006 study. Data source: City of Chicago Department of Environment GIS database, accessed February 1, 2010 [57] Illustration: by authors and modified from Coseo E Larsen [4]. 
Table 5. Descriptive statistics of three-dimensional characterization of land cover in 2010 for eight Chicago neighborhoods.

\begin{tabular}{|c|c|c|c|c|c|c|c|c|}
\hline \multirow{2}{*}{ Neighborhood } & \multirow{2}{*}{$\begin{array}{c}\text { Density } \\
\text { units/hectare }\end{array}$} & \multirow{2}{*}{$\begin{array}{c}\text { Block Area } \\
\mathbf{m}^{2}\end{array}$} & \multicolumn{2}{|c|}{ Impervious Surface Area } & \multicolumn{2}{|c|}{ Pervious Surface Area } & \multicolumn{2}{|c|}{ Tree Canopy Area } \\
\hline & & & $\mathrm{m}^{2}$ & (\% impervious) & $\mathbf{m}^{2}$ & (\% pervious) & $\mathrm{m}^{2}$ & (\% canopy) \\
\hline Wicker Park & 47.4 & 13,462 & 12,879 & $(95.7 \%)$ & 579 & $(4.3 \%)$ & 637 & $(4.7 \%)$ \\
\hline Bronzeville & 35.7 & 40,162 & 32,086 & $(79.9 \%)$ & 8,073 & $(20.1 \%)$ & 7,425 & $(18.5 \%)$ \\
\hline Austin & 35.3 & 19,794 & 14,873 & $(75.1 \%)$ & 4,929 & $(24.9 \%)$ & 3,906 & $(19.7 \%)$ \\
\hline Little Italy & 30.9 & 20,604 & 19,436 & $(94.3 \%)$ & 1,174 & $(5.7 \%)$ & 6,062 & $(29.4 \%)$ \\
\hline Logan Square & 27 & 25,821 & 22,739 & $(88.1 \%)$ & 3,073 & $(11.9 \%)$ & 3,415 & $(13.2 \%)$ \\
\hline Belmont Cragin & 26 & 23,219 & 18,104 & $(78.0 \%)$ & 5,108 & $(22.0 \%)$ & 4,212 & $(18.1 \%)$ \\
\hline East Side & 19.2 & 19,468 & 14,325 & $(73.6 \%)$ & 5,140 & $(26.4 \%)$ & 4,501 & $(23.1 \%)$ \\
\hline Beverly & 14.3 & 22,678 & 12,391 & $(54.6 \%)$ & 10,296 & $(45.4 \%)$ & 13,702 & $(60.4 \%)$ \\
\hline Average & 32 & 23,151 & 18,354 & $(79.3 \%)$ & 4,796 & $(20.7 \%)$ & 5,482 & $(23.7 \%)$ \\
\hline
\end{tabular}


We used HOBO weather stations and Chicago's Midway Airport weather data to calculate the dependent variable, air temperature differences between the eight neighborhoods. We collected weather observations using stationary Onset U23-002 HOBO External Temperature/Relative Humidity weather stations with an accuracy of $\pm 0.2{ }^{\circ} \mathrm{C}$ from 0 to $50{ }^{\circ} \mathrm{C}$ with relative humidity accuracy of $\pm 2.5 \%$ from $10 \%$ to $90 \%$ relative humidity [58] that are protected by a model RS3 solar radiation shield. Each $\mathrm{HOBO}$ was located at the center of each selected block's back alley attached on the north or east side of a utility pole at three-meter height to avoid damage by garbage collection trucks. HOBOs were placed well below the building heights for each neighborhood. All building heights were a minimum 9.14 meters. HOBO units' location and heights were placed using the Initial Guidance to Obtain Representative Meteorological Observations at Urban Sites criteria [59] to establish the most representative location for neighborhood air temperatures near the ground while maintaining security of the stations. The $\mathrm{HOBO}$ collected ambient air temperature and relative humidity from July 1 to August 31, 2010 every 5 minutes for 24 hours a day. We collected Midway Airport hourly weather observations from July 1 to August 31 from Reference [60]. Our approach was to calculate the inter-urban thermal differences between neighborhood climate zones following a similar logic to Stewart and Oke [61] Local Climate Zones. Finding a nonurbanized location to represent pre-settlement conditions with the same elevation and distance to Lake Michigan was problematic. Thus, Midway Airport was selected due to its proximity to the neighborhoods, its status as the preeminent reporter of Chicago weather conditions, and a location Southwest of the other neighborhoods but with similar elevation and distance from Lake Michigan's cooling influence. Midway provides a base case before air moves over the neighborhoods. During warm weather, the predominate wind direction is out of the southwest (210 degrees). O'Hare Airport, to the northwest of Chicago, does not offer this same upwind orientation to selected neighborhoods. We were concerned about choosing Midway Airport, an urbanized location, so we explored rural locations such as Sugar Grove, IL (60 km west of Midway Airport) and the National Weather Service at Romeoville, IL ( $35 \mathrm{~km}$ southwest of Midway Airport). We determined that the reduced influence of Lake Michigan and the topography of the Fox River Valley did not properly represent pre-settlement conditions of the Lake Michigan plain. This led us to include the Beverly neighborhood. The Beverly block represents a location that is within the Lake Michigan plain, not located near a land surface heat island, with extensive tree canopy (60\% coverage), and large percentages of pervious lawn areas ( $45 \%$ with areas under the tree canopy). Situated in the southwestern portions of Chicago, Beverly helps us capture pre-urban-induced heating conditions before air masses move over Chicago's densely built neighborhoods.

We used USGS high resolution (1.0 m) orthoimagery from April 9, 2010 to calculate land cover, building configuration, and adjacent heat source and sink predictor variables based on previous work [citation omitted for anonymous, double-blind review]. Land cover percentages are based on Akbari and colleagues [18] approach to calculating above-the-canopy (two-dimensional) and under-the-canopy (three-dimensional) land covers. Orthoimages were imported into AutoDesk's AutoCAD software, scaled to size, and then each land cover was digitized by hand at fine scales to determine very precise areal coverage of various surface types. AutoCAD, a design software, was used to very precisely determine first square meters of land cover types and then percentages for predictor variables. Land covers were calculated twice for each case study block, once for two-dimensional analysis, and once for three-dimensional analysis. All calculations were a percentage of the whole block including a portion of the street's impervious surface extending from street curb to mid street. For the two-dimensional analysis, the land cover types included 1) roof, 2) road, 3) alley, 4) sidewalks, driveways, and parking lots, 5) tree canopy, and 6) planting areas. For the three-dimensional analysis, we repeated the land cover types \#1-4 and \#6, we excluded tree canopy and calculated land cover types in sun and under tree shade. We did not distinguish between sidewalks, driveways, and parking lots because of the small number of private driveways and parking lots. Calculations for tree canopy include both deciduous shade and coniferous trees. The UHI intensity or the difference in temperature between 
each neighborhood and Midway $\left(\Delta \mathrm{T}_{\text {air }}\right)$ was calculated for 2 a.m. and 4 p.m. for 12 clear days in July and August, 2010.

Ordinary least squares (OLS) regression has been commonly used in similar studies examining the drivers of atmospheric UHIs [62-64]. The OLS regression analysis was conducted in two steps. First, a bivariate analysis identified the most significant relationships between the predictor variables and the difference in air temperatures between our neighborhoods and Midway Airport $\left(\Delta \mathrm{T}_{\text {air }}\right)$. From this we established the most significant bivariate relationships for which to base the OLS regression at both 2 a.m. and 4 p.m. For the OLS regression, we regressed our predictors in three blocks, creating three models for both 2 a.m. and 4 p.m. At 2 a.m. in UHI model 1, we regressed a dummy neighborhood variable against $\Delta \mathrm{T}_{\text {air }}$. In UHI model 2, we added two land cover variables (percent impervious surfaces and percent tree canopy). In UHI model 3, we added urban configuration variables (aspect ratio and orientation). In total, we did not exceed five predictor variables so that we did not exceed our eight cases. For the afternoon analysis we repeated the regression by creating a similar three model approach. At 4 p.m. in UHI model 1, again we regressed a dummy neighborhood variable against $\Delta \mathrm{T}_{\text {air }}$. In UHI model 2, we added that same two land cover variables of percent impervious surfaces and percent tree canopy. In UHI model 3, we added adjacent predictor variables of distance to industry and percentage of upwind tree canopy. We repeated this OLS regression sequence for both two-dimensional and three-dimensional approaches to calculating the predictor variables.

OLS regression is a useful tool to help identify the drivers of urban-heating. However, we acknowledge limitations with OLS regression including multicollinearity [65], predictor selection problems, and addressing overestimates of parameters [66]. To address these issues, we ran an 1) elastic net (EN) regression analysis and 2) variance inflation factor (VIF) in SPSS to test the validity of the OLS models and test how inflated the variance of the predictors variables are due to correlation between variables $[63,66]$. EN regression combines ridge and lasso regression to address instances of small number of dependent variables with a large number of predictor variables and helps address instances where there may be correlation between predictors. Lasso regression picks one of the correlated predictors and eliminates the others, while ridge minimizes the parameter estimates of the correlated predictors [66]. EN leverages the strengths of ridge and lasso to validate OLS regressions and increase confidence in its predictive power. Next, we looked to VIF diagnostics. O'brien [65] cautions on rules of thumb for VIF, but generally low numbers of VIF under 10 or even better under 3 indicate lower levels of multicollinearity. Wicki et al., [63] suggest that models with VIF over 10 may still be useful, but caution should be taken with interpretation. If VIF is high, $\mathrm{O}^{\prime}$ brien [65] suggests one remedy for multicollinearity is to remove collinear predictor variables. Thus, we ran VIF diagnostic for models 2 and 3 to understand if any of the models might suffer from multicollinearity.

\section{Results}

\subsection{Two-Dimensional and Three-Dimensional Land Cover Charaterization Approaches}

First, we wanted to understand how accounting for impervious surfaces under tree canopies affected calculations of land cover types. Table 6 describes percent land cover types using a two-dimensional and three-dimensional approach. For the eight neighborhoods, the average percent impervious surface calculated using a three-dimensional approach $(75.9 \%)$ was $+14.1 \%$ higher than using a two-dimensional approach $(65.8 \%)$. In neighborhoods with the highest amount of tree canopy (60\% tree canopy in Beverly and 30\% tree canopy in Little Italy), more than $25 \%$ of impervious surfaces were missed with a two-dimensional approach. Wicker Park had the smallest amount of undocumented impervious surfaces. Undocumented impervious surfaces in Wicker Park were only $4.3 \%$ of the total land cover. Although both Little Italy and Wicker Park have high amounts of impervious surface, Little Italy has substantially greater tree canopy coverage than Wicker Park. We ran a t-test on the paired difference in the means of the percent impervious surface for all the neighborhoods using the 
two approaches and found that overall the difference of using a three-dimensional approach was significantly different $(\mathrm{p}<0.000$ level) than using a two-dimensional approach.

Overall, using a two-dimensional approach the most commonly missed impervious land cover types were sidewalks, driveways, and parking lots (6.2\%), followed closely by roads (6.1\%). Yet, this did not necessarily vary only with tree canopy. Beverly had the highest percent tree canopy. However, Beverly's low density (11.7 units/hectare) resulted in planting areas (lawns or gardens) being the most undocumented land cover types (increasing by $+34.6 \%$ with a three-dimensional approach). Little Italy with the second highest density (43.7 units/hectare) also had the second highest percent tree canopy $(29.4 \%)$. By documenting impervious surfaces under tree canopies the calculations of road surfaces went from $3.2 \%$ (two-dimensional) to $17.3 \%$ (three-dimensional) of total cover types (increasing by $+14.1 \%$ ) and sidewalks, driveways, and parking lots went from $20.9 \%$ to $33.7 \%$ of total cover types (increasing by $+12.8 \%$ ). The combination of moderate to high tree canopy and high density resulted in substantial areas of impervious surface to go undocumented in Little Italy by using a two-dimensional approach. Documenting impervious surfaces under tree canopies significantly improved the description of impervious land covers in medium density neighborhoods with moderate to high amounts of tree canopy.

However, we found that using a three-dimensional approach is not as critical to accurately describing impervious land cover types in a neighborhood with either 1) low amounts of tree canopy such as Wicker Park or 2) higher percentages of tree canopy and lower density of units per hectare such as Beverly. In addition, roofs and alleys were the least affected by tree canopy concealment. With the exception of Beverly, the lack of tree canopy adjacent to the alleys resulted in little, if any, difference between the calculations. Although using a three-dimensional approach provides a more accurate account of impervious surfaces in neighborhoods with heavy tree canopies and higher densities, we wanted to know how documenting impervious surfaces under tree canopies affects a UHI model's explanatory power. 
Table 6. Descriptive statistics of two (2-D) and three-dimensional (3-D) characterization of land cover variables in 2010 for eight neighborhoods.

\begin{tabular}{|c|c|c|c|c|c|c|c|c|c|c|c|c|c|c|c|c|c|c|c|}
\hline \multicolumn{20}{|c|}{ Cover-type (percent of total cover for two-dimensional and percent increase using three-dimensional) } \\
\hline \multirow[t]{2}{*}{ Neighborhood } & \multicolumn{3}{|c|}{$\begin{array}{c}\% \text { Impervious Surface } \\
\text { Area }\end{array}$} & \multicolumn{3}{|c|}{$\%$ Roof } & \multicolumn{3}{|c|}{$\%$ Road } & \multicolumn{3}{|c|}{$\%$ Alley } & \multicolumn{3}{|c|}{$\begin{array}{c}\text { \% Sidewalks, } \\
\text { Driveways, and } \\
\text { Parking Lots }\end{array}$} & \multirow{2}{*}{$\begin{array}{c}\begin{array}{c}\text { Tree } \\
\text { Canopy }\end{array} \\
\text { 2-D }\end{array}$} & \multicolumn{3}{|c|}{ Pervious Surface Area } \\
\hline & 2-D & 3-D & $(\% \Delta)$ & 2-D & 3-D & $(\% \Delta)$ & 2-D & 3-D & $(\% \Delta)$ & 2-D & 3-D & $(\% \Delta)$ & 2-D & 3-D & $(\% \Delta)$ & & 2-D & 3-D & $(\% \Delta)$ \\
\hline Little Italy & 66.5 & 94.3 & $(+27.8)$ & 38.3 & 39.1 & $(+0.8)$ & 3.2 & 17.3 & $(+14.1)$ & 4.1 & 4.2 & $(+0.1)$ & 20.9 & 33.7 & $(+12.8)$ & 29.4 & 4.1 & 5.7 & $(+1.6)$ \\
\hline Beverly & 28.9 & 54.6 & $(+25.7)$ & 16.3 & 22.9 & $(+6.6)$ & 4.5 & 11.6 & $(+7.1)$ & 1.6 & 4.7 & $(+3.1)$ & 6.5 & 15.6 & $(+9.1)$ & 60.4 & 10.7 & 45.4 & $(+34.7)$ \\
\hline East Side & 59.8 & 73.6 & $(+13.8)$ & 31 & 31.9 & $(+0.9)$ & 7.5 & 14.5 & $(+7)$ & 3.7 & 3.8 & $(+0.1)$ & 17.6 & 23.5 & $(+5.9)$ & 23.1 & 17.1 & 26.4 & $(+9.3)$ \\
\hline Belmont Cragin & 66.2 & 78 & $(+11.8)$ & 36.9 & 37.9 & $(+1)$ & 6.7 & 13.3 & $(+6.6)$ & 4 & 4.1 & $(+0.1)$ & 18.6 & 22.7 & $(+4.1)$ & 18.1 & 15.7 & 22.1 & $(+6.4)$ \\
\hline Bronzeville & 69.5 & 79.9 & $(+10.4)$ & 21.6 & 21.8 & $(+0.2)$ & 12.6 & 16.9 & $(+4.3)$ & 4.2 & 4.5 & $(+0.3)$ & 31.2 & 36.8 & $(+5.6)$ & 18.5 & 12 & 20.1 & $(+8.1)$ \\
\hline Austin & 65.5 & 75.1 & $(+9.6)$ & 27.1 & 28.2 & $(+1.1)$ & 10.9 & 14.4 & $(+3.5)$ & 4.1 & 4.2 & $(+0.1)$ & 23.4 & 28.4 & $(+5)$ & 19.7 & 14.8 & 24.9 & $(+10.1)$ \\
\hline Logan Square & 78.8 & 88.1 & $(+9.3)$ & 37.3 & 37.9 & $(+0.6)$ & 11.9 & 16.8 & $(+4.9)$ & 7 & 7.01 & $(+0.01)$ & 22.6 & 26.4 & $(+3.8)$ & 13.2 & 8 & 12 & $(+4)$ \\
\hline Wicker Park & 91.4 & 95.7 & $(+4.3)$ & 34 & 34.02 & $(+0.02)$ & 23.8 & 24.9 & $(+1.1)$ & 6.2 & 6.3 & $(+0.1)$ & 27.4 & 30.4 & $(+3)$ & 4.7 & 3.9 & 4.4 & $(+0.5)$ \\
\hline Average & 65.8 & 79.9 & $(+14.1)^{* *}$ & 30.3 & 31.7 & $(+1.4)$ & 10.1 & 16.2 & $(+6.1)$ & 4.4 & 4.9 & $(+0.5)$ & 21 & 27.2 & $(+6.2)$ & 23.4 & 10.8 & 20.1 & $(+9.3)$ \\
\hline
\end{tabular}

** $p<0.000$ level using paired samples test of the difference in percent mean impervious surface area for eight Chicago neighborhoods using a two-dimensional compared to three-dimensional approach. 


\subsection{Explanatory Power of Two-Dimensional and Three-Dimensional Approaches}

Next, we examined if characterizing land cover variables using a three-dimensional approach improved the explanatory power of a UHI model over using a two-dimensional approach. We took an UHI model used in a related study of Chicago UHIs [4] to test the different approaches. We regressed five predictor variables in blocks against the difference in air temperature $\left(\Delta \mathrm{T}_{\text {air }}\right)$ between the eight neighborhoods and Midway Airport for 2 a.m. and 4 p.m. for 12 clear days in the summer of 2010. We also ran 1) elastic net (EN) regression analysis and 2) VIF diagnostics to test for multicollinearity between predictor variables for each block and combined that by an elastic net (EN) analysis to ensure the validity of the OLS analysis. A model with multicollinearity allows for it to be used for prediction, but not inference of the individual predictors variables coefficients.

At 2 a.m. the predictor variables entered included block 1) neighborhood location, block 2) land cover variables for two-dimensional percent impervious surfaces and percent tree canopy, block 3) neighborhood configuration variables for the aspect ratio and a dummy variable representing either north-south or east-west orientation. Running the elastic net (EN) test, we found that the OLS models, while not as accurate as the EN models, performed generally well. For brevity we only report UHI model 3 at 2 am for the comparison of OLS and EN for the three-dimensional approach (see Appendix A for comparison). OLS and EN had similar adjusted $\mathrm{R}^{2}$ (OLS, 0.676 versus EN, 0.690 ) with comparable standardized coefficients for percent tree canopy (OLS, -0.190 versus EN, -0.189 ), while percent impervious surface area was directionally consistent but OLS may have overestimated this variable (OLS, 0.818 versus EN, 0.200). Hence, we feel confident that the OLS is performing reasonably well for prediction, although caution should be exercised in interpreting the results with predictor coefficients. Next, testing VIF for multicollinearity, we found that model 3 for both the three-dimensional and two-dimensional had predictor variables with VIF above 10, indicating multicollinearity. O'brien [65] suggests one fix for multicollinearity is to remove variables, so we looked at model two. Model 2 for both two- and three-dimensional approaches had VIF just over 1.0, indicating lack of multicollinearity. Thus, although model 3 could be used for prediction, we cannot interpret the predictor variables. Due to this issue with multicollinearity in model 3, we report on model 2 for 2 a.m. We also found that adding aspect ratio and orientation predictor variables in model 3 did not improve the explanatory power for either the two or three-dimensional approaches.

At 2 a.m. substituting the three-dimensional calculations for the two-dimensional calculations of percent impervious surface increased the explanatory power slightly from 0.64 (two-dimensional, Table 7) to 0.68 (three-dimensional, Table 8) for model 2. Running the model with the two-dimensional and the three-dimensional calculations did not affect the significant predictors. Percent impervious surface and percent tree canopy were both significant predictors using both two- and three-dimensional approaches. Both methods had slightly different coefficients for percent impervious of 10.41 (two-dimensional) and 7.42 (three-dimensional). Controlling for all other factors, for every $10 \%$ increase in two-dimensional and three-dimensional calculations of impervious surfaces of the block we would expect a warming of the neighborhood relative to Midway by $+1.04{ }^{\circ} \mathrm{C}$ (two-dimensional) and $+0.74{ }^{\circ} \mathrm{C}$ (three-dimensional) at $2 \mathrm{a}$.m. The two-dimensional approach overestimated the warming for a $10 \%$ increase in impervious surface by $+0.30^{\circ} \mathrm{C}$ over the more accurate three-dimensional approach. The two-dimensional approach resulted in percent tree canopy accounting for $+0.41^{\circ} \mathrm{C}$ of warming for every $10 \%$ increase in tree canopy to $-0.21^{\circ} \mathrm{C}$ of cooling for every $10 \%$ increase in tree canopy by more accurately accounting for land cover variables. At 2 a.m., using the more accurate three-dimensional land cover calculations for impervious surface area did not result in significantly greater explanatory power and the predictors were the same. However, the coefficients were different and the direction of tree canopy predicator variable switched from a warming influence (two-dimensional) to a cooling influence (three-dimensional). For both two and three-dimensional approaches the significance levels for percent impervious surface $(\mathrm{p}<0.005)$ provides more confidence in the finding than percent tree canopy $(\mathrm{p}<0.05)$. 
Table 7. Regression analysis for UHI temperatures at 2 a.m. using two-dimensional approach in eight Chicago neighborhoods in summer 2010.

\begin{tabular}{|c|c|c|c|c|c|c|c|c|c|}
\hline \multirow{2}{*}{ Variable } & \multicolumn{3}{|c|}{ Model 1} & \multicolumn{3}{|c|}{ Model 2} & \multicolumn{3}{|c|}{ Model 3} \\
\hline & B & SE & Beta & B & SE & Beta & B & $\mathrm{SE}$ & Beta \\
\hline Neighborhood & $-0.12^{* * *}$ & 0.05 & -0.23 & $-0.09^{* *}$ & 0.03 & -0.17 & $-0.11^{* * *}$ & 0.04 & -0.20 \\
\hline $\begin{array}{l}\% \text { two-dimensional } \\
\text { Impervious }\end{array}$ & & & & $10.41^{* * *}$ & 1.90 & 1.19 & $9.75^{*}$ & 4.70 & 1.11 \\
\hline \% Tree Canopy & & & & $4.13^{*}$ & 2.05 & 0.44 & 4.47 & 4.01 & 0.47 \\
\hline Aspect Ratio & & & & & & & 1.01 & 1.75 & 0.12 \\
\hline Orientation & & & & & & & -0.40 & 0.31 & -0.14 \\
\hline (Constant) & $1.58^{*}$ & 0.31 & & $-6.41^{* * *}$ & 1.73 & & -6.17 & 3.51 & \\
\hline$n$ & & & 96 & & & 96 & & & 96 \\
\hline Adjusted R2 & & & 0.04 & & & $0.64^{* * *}$ & & & 0.64 \\
\hline Change in R2 & & & & & & 0.60 & & & 0.01 \\
\hline
\end{tabular}

${ }^{*} \mathrm{p}<0.05 .{ }^{* *} \mathrm{p}<0.01 .{ }^{* * *} \mathrm{p}<0.005$ (one-tailed tests).

Table 8. Regression analysis for UHI temperatures at 2 a.m. using three-dimensional approach in eight Chicago neighborhoods in summer 2010.

\begin{tabular}{|c|c|c|c|c|c|c|c|c|c|}
\hline \multirow{2}{*}{ Variable } & \multicolumn{3}{|c|}{ Model 1} & \multicolumn{3}{|c|}{ Model 2} & \multicolumn{3}{|c|}{ Model 3} \\
\hline & B & SE & Beta & B & $\mathrm{SE}$ & Beta & B & SE & Beta \\
\hline Neighborhood & $-0.12^{*}$ & 0.05 & -0.23 & -0.05 & 0.03 & -0.09 & -0.02 & 0.04 & -0.04 \\
\hline $\begin{array}{l}\% \text { three-dimensional } \\
\text { Impervious }\end{array}$ & & & & $7.42^{* * *}$ & 1.12 & 0.63 & $9.66^{* * *}$ & 2.58 & 0.82 \\
\hline \% Tree Canopy & & & & $-2.07^{*}$ & 0.88 & -0.22 & -1.80 & 1.04 & -0.19 \\
\hline Aspect Ratio & & & & & & & -1.58 & 1.74 & -0.19 \\
\hline Orientation & & & & & & & 0.18 & 0.35 & 0.06 \\
\hline (Constant) & $1.58^{* * *}$ & 0.31 & & $-4.23^{* * *}$ & 1.11 & & $-5.67^{* * *}$ & 1.84 & \\
\hline$n$ & & 96 & & & 96 & & & 96 & \\
\hline Adjusted R2 & & & 0.04 & & & $0.68^{* * * *}$ & & & 0.68 \\
\hline Change in R2 & & & & & & 0.64 & & & 0.00 \\
\hline
\end{tabular}

${ }^{*} \mathrm{p}<0.05 .{ }^{* *} \mathrm{p}<0.01 .{ }^{* * *} \mathrm{p}<0.005$ (one-tailed tests).

Similarly, at 4 p.m., we found only slight variation using the more accurate calculations. At 4 p.m. the predictor variables entered included block 1) neighborhood location, block 2) land cover variables for two-dimensional percent impervious surfaces and percent tree canopy, block 3) adjacent heat sources and sinks variables for the distance to industry and upwind percent tree canopy variable representing air displacement from upwind locations. For prediction, model 3 at 4 p.m. substituting the three-dimensional calculations for the two-dimensional calculations of percent impervious surface left the explanatory power from 0.26 (two-dimensional, Table 9) to 0.26 (three-dimensional, Table 10). As at 2 a.m., testing VIF for multicollinearity, we found that model 3 for both the three-dimensional and two-dimensional had predictor variables with VIF above 10, indicating multicollinearity. We again removed variables, so we looked at model 2, which had VIF just over 1.0. Similar to 2 a.m., running model 2 at 4 p.m. with the two-dimensional and the three-dimensional calculations affected the significant predictors with impervious surfaces significant for two-dimensional approach and not significant for three-dimensional approach. Using both two- and three-dimensional approaches percent tree canopy was the only common significant predictor. At 4 p.m. the coefficients for percent tree canopy were slightly different with coefficients of -0.99 (two-dimensional) and -0.47 (three-dimensional). Using the two-dimensional calculations during the afternoon, for every $10 \%$ increase in tree canopy the neighborhood's air temperature was $-0.99^{\circ} \mathrm{C}$ cooler compared to $-0.47^{\circ} \mathrm{C}$ cooler using a three-dimensional approach. For both two and three-dimensional approaches the significance levels for percent tree canopy $(\mathrm{p}<0.005)$ provides more confidence than the significance of the two-dimensional model 2 percent impervious surface $(\mathrm{p}<0.05)$. For UHI predictive models, overall, we found that using more accurate three-dimensional characterization of impervious surface calculations did not significantly improve the model's performance at either 2 a.m. or 4 p.m., but choice of models 2 or 3 may constrain interpretation of the predictor's coefficients. 
Table 9. Regression analysis for UHI temperatures at 4 p.m. using two-dimensional approach in eight Chicago neighborhoods in summer 2010.

\begin{tabular}{|c|c|c|c|c|c|c|c|c|c|}
\hline \multirow{2}{*}{ Variable } & \multicolumn{3}{|c|}{ Model 1} & \multicolumn{3}{|c|}{ Model 2} & \multicolumn{3}{|c|}{ Model 3} \\
\hline & B & SE & Beta & B & SE & Beta & B & $\mathrm{SE}$ & Beta \\
\hline Neighborhood & -0.05 & 0.05 & -0.10 & -0.03 & 0.05 & -0.06 & -0.03 & 0.05 & -0.05 \\
\hline $\begin{array}{l}\text { \% two-dimensional } \\
\text { Impervious }\end{array}$ & & & & $-5.84^{*}$ & 2.64 & -0.71 & -4.27 & 2.92 & -0.52 \\
\hline$\%$ Tree Canopy & & & & $-9.85^{* * *}$ & 2.84 & -1.12 & -4.49 & 5.21 & -0.51 \\
\hline Distance to Industry & & & & & & & $-0.37^{*}$ & 0.16 & -0.42 \\
\hline Upwind \% Tree Canopy & & & & & & & -0.01 & 0.04 & -0.09 \\
\hline (Constant) & $1.86^{* * *}$ & 0.29 & & $7.93^{*}$ & 2.40 & & $6.62^{*}$ & 2.56 & \\
\hline$n$ & & 96 & & & 96 & & & 96 & \\
\hline Adjusted R2 & & & -0.00 & & & $0.21^{* * *}$ & & & $0.26^{*}$ \\
\hline Change in R2 & & & & & & 0.23 & & & 0.07 \\
\hline
\end{tabular}

${ }^{*} \mathrm{p}<0.05 .{ }^{* *} \mathrm{p}<0.01 .{ }^{* * *} \mathrm{p}<0.005$ (one-tailed tests).

Table 10. Regression analysis for UHI temperatures at 4 p.m. using three-dimensional approach in eight Chicago neighborhoods in summer 2010.

\begin{tabular}{|c|c|c|c|c|c|c|c|c|c|}
\hline \multirow{2}{*}{ Variable } & \multicolumn{3}{|c|}{ Model 1} & \multicolumn{3}{|c|}{ Model 2} & \multicolumn{3}{|c|}{ Model 3} \\
\hline & B & $\mathrm{SE}$ & Beta & B & SE & Beta & B & SE & Beta \\
\hline Neighborhood & -0.05 & 0.05 & -0.10 & -0.04 & 0.05 & -0.08 & -0.036 & 0.049 & -0.072 \\
\hline $\begin{array}{l}\% \text { three-dimensional } \\
\text { Impervious }\end{array}$ & & & & -1.38 & 1.68 & -0.13 & -2.10 & 1.97 & -0.20 \\
\hline$\%$ Tree Canopy & & & & $-4.65^{* * *}$ & 1.32 & -0.53 & -0.86 & 3.75 & -0.10 \\
\hline Distance to Industry & & & & & & & $-0.45^{*}$ & 0.18 & -0.51 \\
\hline Upwind \% Tree Canopy & & & & & & & -0.01 & 0.05 & -0.08 \\
\hline (Constant) & $1.86^{* * *}$ & 0.29 & & $4.00^{*}$ & 1.66 & & $4.92^{* *}$ & 1.83 & \\
\hline$n$ & & 96 & & & 96 & & & 96 & \\
\hline Adjusted R2 & & & -0.00 & & & & & & $0.26^{* * *}$ \\
\hline Change in R2 & & & & & & 0.19 & & & 0.09 \\
\hline
\end{tabular}

${ }^{*} \mathrm{p}<0.05 .{ }^{* *} \mathrm{p}<0.01 .{ }^{* * *} \mathrm{p}<0.005$ (one-tailed tests).

\section{Discussion}

Many blocks in Chicago neighborhoods have much higher impervious surfaces than previously reported $[40,44]$. Using a very detailed three-dimensional approach, we found instances of much larger percentages of impervious surfaces than even the Akbari and Rose [29] study. Whereas they found Pilsen and Wrigelyville had $71.3 \%$ and $75.6 \%$ impervious surface area, respectively, we found Little Italy (94.3\%) and Wicker Park (95.7\%) had much higher percentages of impervious surface areas at the sub-neighborhood scale. This is likely due to the scale of investigation. At the neighborhood scale, Little Italy and Wicker Park have parks and other pervious areas that would reduce the total percentage of impervious surfaces per neighborhood. Essentially, when we sampled at the block area, impervious surfaces in and around buildings were very common. In urban neighborhoods, such as Chicago, it is not uncommon to have block and street typologies that have little to no pervious areas. That is not to say that these neighborhoods do not have tree canopy. As was the case in Little Italy with almost 30\% tree canopy, a common urban forestry practice in many cities is to plant trees in tree pits, with very little to no pervious surface. The openings for tree pits can range for just enough space for the tree trunk with asphalt or pavement right up to the trunk to tree grate as small as $1.2 \times 1.2$ meters.

In the eight neighborhoods, the three-dimensional approach on average resulted in the documentation of an additional $+6.2 \%$ sidewalks, driveways, and parking lot surfaces and an additional $+6.1 \%$ road pavement surfaces. Yet, neighborhood tree canopy alone does not necessary explain all of the differences in concealing impervious surfaces. We found that it was a combination of compactness and tree canopy that resulted in concealing many of the impervious surfaces. For example, we found that using a three-dimensional approach was more useful in Little Italy where a combination of moderate tree canopy (30\%) and high compactness of buildings (43.7 units/hectare) obscured more impervious surfaces than in Wicker Park with low tree canopy (4.7\%) and high compactness 
(63.5 units/hectare). In Little Italy, substantial areas of impervious roads $(+14.1 \%)$ and sidewalks, driveways, and parking lots $(+12.8 \%)$ went undocumented by using a two-dimensional approach. This compares to Akbari and Rose [29], who found $+10.6 \%$ more impervious surfaces ( $75.6 \%$ of total area) in Chicago's Wrigleyville with $+3.0 \%$ more from roads and $+7.3 \%$ more from miscellaneous surfaces. Those miscellaneous surfaces may very well have been alley surfaces, as we found that alley surfaces accounted for between 3.8\% (East Side) to 7.1\% (Logan Square) the block's total surface area.

These findings are generally more than the additional $+11 \%$ paved areas that Akbari and colleagues [18] found in downtown Sacramento, CA, where they also examined eight residential neighborhoods. The Sacramento neighborhood of East Downtown with the most impervious surface had just less than $70 \%$ impervious surface (accounting for land covers under the tree canopy) and $27 \%$ tree canopy. Accounting for under the canopy road surfaces raised percentages of roads by $+9.5 \%$ over two-dimensional analysis [18]. This is similar to the findings for Little Italy. Lastly, we found using a two-dimensional approach generally represented an accurate account of percent roof and alley surfaces. The exception was in lower density neighborhoods with lower building heights and high amounts of trees. In Beverly, we found a three-dimensional approach documented an additional $+6.6 \%$ roof surfaces and $+3.1 \%$ of alleys surfaces. High density neighborhoods with taller buildings and mature street trees planted in wells, such as Little Italy, primarily obscured ground level impervious surfaces.

Finally, we found that using three-dimensional characterizations of land covers did not substantially improve the explanatory power of a UHI model. However, it likely impacts interpretation of the model's predictors. Past studies of three-dimensional approaches have not tested more accurate characterization of impervious surface calculations to understand how they might improve UHI models $[18,29-31,37]$. Running the UHI model with both two-dimensional and three-dimensional calculations of percent impervious surface improved the explanatory power slightly at 2 a.m., but decreased the explanatory power slightly at 4 p.m. At 2 a.m. the UHI model 2 improved from 0.64 (two-dimensional) to 0.68 (three-dimensional). The 2 a.m. UHI model 2 two-dimensional approach overestimated the warming from impervious surfaces and resulted in percent tree canopy switching from a warming variable to a cooling land cover variable. Accounting for the additional heating from the obscured impervious surface should have resulted in a more accurate model to infer the implications for design and planning. In this case, the 2 a.m. model 2 (three-dimensional) suggests that tree canopies in the eight Chicago neighborhoods likely provide some cooling at night. Trees in urban canyons reduce the sky view factor and the efficient escape of longwave radiation at night creating warming, but that is also balanced by the shading of impervious surfaces from absorbing daytime radiation. Coutts and colleagues [24] suggests strategic placement of trees to shade sun-exposed structures and surfaces, but still spaced for nighttime longwave escape. Especially since the direction of influence changed between a less accurate and more accurate approach to calculating impervious surfaces, caution should be taken with implications and more research should examine this modelling pattern.

At 4 p.m. UHI prediction is more difficult due to the complicated radiative environment, higher daytime winds that mix the atmosphere [63], and in Chicago, lake breezes commonly develop in the late afternoon [40]. During the day, the 4 p.m. UHI model 2 remained similar ranging between 0.21 (two-dimensional) and 0.17 (three-dimensional), and its explanatory power was much less than the nighttime models. Overall, both night and daytime analysis suggests that using three-dimensional characterization of land cover variables does not substantially improve UHI model predictive power over using two-dimensional characterizations, but it may likely impact researchers' ability to infer about the predictor's relative impact on urban-induced warming.

\section{Conclusions}

Addressing UHIs has risen to the top of many cities' urban planning agendas. Yet, researchers, urban planners, designers, and decision-makers still struggle to justify heat mitigation actions due to lack of knowledgeable experts, cost of data collection, and other competing priorities. This study provides a relative understanding of the trade-offs in accuracy for quantifying urban land covers and 
how that might impact UHI analysis. For UHI analysis, although the three-dimensional approach more accurately describes ground level land covers, the findings suggest that two-dimensional calculations of land cover variables are likely sufficient for predicting UHIs. Yet for UHI reduction, the three-dimensional approach to quantifying land cover types improves the ability to infer relative impact of predictor variables and the description of ground level land covers, which is important for tree and vegetation planting programs, programs to reduce impervious surface areas, stormwater management programs, and programs to change land cover type. This is especially the case where a combination of moderate to high tree canopies obscure impervious surfaces in dense urban areas.

This study has several limitations. First, OLS regression has short comings with the low number of neighborhood cases and multicollinearity issues as discussed earlier. Other statistical techniques that have been used to address these shortcomings include elastic net [66], as used in this article, and random forest [67]. Second, we were only able to document land cover's relationship to air temperature in eight neighborhoods in a temperate urban climate. This study did not include land surface temperatures derived from satellite imagery. Finally, tree type was not considered in this analysis. Tree type likely would affect the transmittance of incoming shortwave radiation that reaches ground impervious surfaces.

A promising advancement to more accurate characterization of predictor variables for UHI modeling includes the use of combinations of LiDAR with National Agricultural Imagery Program imagery [68] or Google Street Views [69]. In particular, Middel and colleagues' [70] efforts to leverage big data methods to better represent the three-dimensional urban environmental are particularly promising. With these new methods, future research should consider adding more neighborhoods, adding sites from various cities that include a broader range of climate zones and urban forms, documenting tree type, and combining this analysis with land surface temperatures. These future examinations also should examine the role of shade and its impact not only on heating and cooling ground level urban surfaces, but also impacts for human thermal comfort. In particular, attention should be given to the multitude of gradients of shade produced by the transmittance of radiation through tree canopies and structural shade elements.

Author Contributions: Both P.C. and L.L. co-developed the conceptualization of the study. P.C. was primarily responsible for the site visits and the field data collection. The analysis was co-developed by both authors. P.C. had the leading role in preparing the manuscript drafts and visualizations with frequent reviews, editing, and writing by L.L. Both authors contributed substantially to the work reported.

Funding: This research was funded by the Graham Environmental Sustainability Institute. We would like to thank them for their financial support of this research.

Acknowledgments: We would like to thank Marie O'Neill for the use of her HOBO weather stations. We would also like to thank Scott Campbell and Richard Norton for their recommendations for the study. Finally, we would like to thank the Chicago Department of Transportation for the logistical support that made the study possible.

Conflicts of Interest: The authors declare no conflict of interest. The funders had no role in the design of the study; in the collection, analyses, or interpretation of data; in the writing of the manuscript, or in the decision to publish the results. 


\section{Appendix A}

\begin{tabular}{|c|c|c|c|c|c|c|c|c|}
\hline \multicolumn{4}{|c|}{ SPSS Elastic Net Regression Analysis compared with OLS Regression, Model 3 at 2 am } & \multicolumn{5}{|c|}{ Standardized Coefficients (Beta) } \\
\hline & Ridge Penalty & Lasso Penalty & $\begin{array}{c}\text { Adjusted R }{ }^{2} \\
\text { (Mean Squared Error) }\end{array}$ & $\begin{array}{l}\text { Neighborhood } \\
\text { Number }\end{array}$ & $\begin{array}{l}\text { Percent } \\
\text { Impervious }\end{array}$ & $\begin{array}{l}\text { Percent Tree } \\
\text { Canopy }\end{array}$ & Aspect Ratio & Orientation \\
\hline Selected Elastic Net Model 3 at 2 am, two-dimensional, Step 560 & 1.0 & 0.98 & $0.688(0.371)$ & 0.000 & 0.196 & -0.191 & 0.199 & 0.000 \\
\hline OLS Regression Model 3 at 2am, two-dimensional & & & $0.642(0.881)$ & -0.201 & 1.112 & 0.473 & 0.122 & -0.137 \\
\hline Selected Elastic Net Model 3 at 2 am, three-dimensional, Step 560 & 1.0 & 0.98 & $0.690(0.369)$ & 0.000 & 0.200 & -0.189 & 0.197 & 0.000 \\
\hline OLS Regression Model 3 at 2 am, three-dimensional & & & $0.676(0.839)$ & -0.043 & 0.818 & -0.190 & -0.192 & 0.062 \\
\hline \multicolumn{4}{|c|}{ SPSS Elastic Net Regression Analysis compared with OLS Regression, Model 3 at 4 pm } & \multicolumn{5}{|c|}{ Standardized Coefficients (Beta) } \\
\hline & Ridge Penalty & Lasso Penalty & $\begin{array}{c}\text { Adjusted R }{ }^{2} \\
\text { (Mean Squared Error) }\end{array}$ & $\begin{array}{l}\text { Neighborhood } \\
\text { Number }\end{array}$ & $\begin{array}{l}\text { \% Impervious } \\
\text { Surface }\end{array}$ & \% Tree Canopy & $\begin{array}{l}\text { Distance to } \\
\text { Industry }\end{array}$ & $\begin{array}{l}\text { Upwind \% } \\
\text { Tree Canopy }\end{array}$ \\
\hline Selected Elastic Net Model 3 at 4 pm, two-dimensional, Step 98 & 0.20 & 0.04 & $0.217(.823)$ & 0.134 & -0.270 & -0.175 & -0.244 & -0.179 \\
\hline OLS Regression Model 3, at 4 pm, two-dimensional & & & $0.262(1.181)$ & -0.053 & -0.523 & -0.509 & -0.086 & -0.423 \\
\hline Selected Elastic Net Model 3 at 4pm, three-dimensional, step 466 & 0.90 & 0.86 & $0.220(0.701)$ & 0.000 & 0.000 & 0.000 & -0.056 & 0.000 \\
\hline OLS Regression Model 3 at $4 \mathrm{pm}$, three-dimensional & & & $0.255(1.187)$ & -0.072 & -0.199 & -0.097 & -0.506 & -0.083 \\
\hline
\end{tabular}




\section{References}

1. Stone, B.J. The City and the Coming Climate: Climate Change in the Places We Live; Cambridge University Press: New York, NY, USA, 2012.

2. Gartland, L. Heat islands: Understanding and Mitigating Heat in Urban Areas; Earthscan: Sterling, VA, USA, 2008.

3. Imhoff, M.L.; Zhang, P.; Wolfe, R.E.; Bounoua, L. Remote sensing of the urban heat island effect across biomes in the continental USA. Remote Sens. Environ. 2010, 114, 504-513. [CrossRef]

4. Coseo, P.; Larsen, L. How factors of land use/land cover, building configuration, and adjacent heat sources and sinks explain Urban Heat Islands in Chicago. Landsc. Urban Plan. 2014, 125, 117-129. [CrossRef]

5. Stewart, I.D. A systematic review and scientific critique of methodology in modern urban heat island literature. Int. J. Climatol. 2011, 31, 200-217. [CrossRef]

6. Memon, A.R.; Leung, D.Y.C.; Chunho, L. A review on the generation, determination and mitigation of Urban Heat Island. J. Environ. Sci. 2008, 20, 120-128.

7. O'Neill, M.S.; Zanobetti, A.; Schwartz, J. Disparities by race in heat-related mortality in four US cities: The role of air conditioning prevalence. J. Urban Heal. 2005, 82, 191-197. [CrossRef] [PubMed]

8. Harlan, S.L.; Brazel, A.J.; Prashad, L.; Stefanov, W.L.; Larsen, L. Neighborhood microclimates and vulnerability to heat stress. Soc. Sci. Med. 2006, 63, 2847-2863. [CrossRef] [PubMed]

9. U.S. Environmental Protection Agency. Urban Heat Island Mitigation. Retrieved. 2012. Available online: http://www.epa.gov/hiri/mitigation/index.htm (accessed on 7 January 2012).

10. Arnold, C.L.; Gibbons, C.J. Impervious Surface Coverage: The Emergence of a Key Environmental Indicator. J. Am. Plan. Assoc. 1996, 62, 243-258. [CrossRef]

11. Hough, M. Cities and Natural Processes; Routledge: New York, NY, USA, 2004.

12. Alberti, M. Advances in Urban Ecology; Spring: New York, NY, USA, 2008.

13. U.S. Environmental Protection Agency. Heat Island Impacts. 2012. Available online: http://www.epa.gov/ hiri/impacts/index.htm (accessed on 11 May 2012).

14. Zhang, K.; Oswald, E.M.; Brown, D.G.; Brines, S.J.; Gronlund, C.J.; White-Newsome, J.L.; Rood, R.B.; O'neill, M.S. Geostatistical exploration of spatial variation of summertime temperatures in the Detroit metropolitan region. Environ. Res. 2011, 111, 1046-1053. [CrossRef]

15. Stone, B., Jr.; Rodgers, M.O. Urban Form and Thermal Efficiency: How the design of cities influences the urban heat island effect. J. Am. Plan. Assoc. 2001, 67, 186-198. [CrossRef]

16. Coutts, A.; Beringer, J.; Tapper, N.J. Impact of Increasing Urban Density on Local Climate: Spatial and Temporal Variations in the Surface Energy Balance in Melbourne, Australia. J. Appl. Meteorol. Climatol. 2007, 46, 477-493. [CrossRef]

17. Debbage, N.; Shepherd, J.M. Computers, Environment and Urban Systems The urban heat island effect and city contiguity. CEUS 2015, 54, 181-194.

18. Akbari, H.; Shea Rose, L.; Taha, H. Analyzing the land cover of an urban environment using high-resolution orthophotos. Landsc. Urban Plan. 2003, 63, 1-14. [CrossRef]

19. Pauleit, S.; Duhme, F. Assessing the environmental performance of land cover types for urban planning. Landsc. Urban Plan. 2000, 52, 1-20. [CrossRef]

20. U.S. Environmental Protection Agency. Reducing Urban Heat Islands: Compendium of Strategies, Cool Pavements. 2012. Available online: www.epa.gov/hiri/resources/pdf/CoolPavesCompendium.pdf (accessed on 11 May 2012).

21. Synnefa, A.; Santamouris, M.; Apostolakis, K. On the development, optical properties and thermal performance of cool colored coatings for the urban environment. Sol. Energy 2007, 81, 488-497. [CrossRef]

22. Golden, J.S.; Kaloush, K.E. Mesoscale and microscale evaluation of surface pavement impacts on the urban heat island effects. Int. J. Pavement Eng. 2006, 7, 37-52. [CrossRef]

23. Oke, T.R. Boundary Layer Climates; University Press: Cambridge, UK, 1987.

24. Coutts, A.M.; Harris, R.J.; Phan, T.; Livesley, S.J.; Williams, N.S.G.; Tapper, N.J. Thermal infrared remote sensing of urban heat: Hotspots, vegetation, and an assessment of techniques for use in urban planning. Remote Sens. Environ. 2016, 186, 637-651. [CrossRef]

25. Bowler, D.E.; Buyung-Ali, L.; Knight, T.M.; Pullin, A.S. Urban greening to cool towns and cities: A systematic review of the empirical evidence. Landsc. Urban Plan. 2010, 97, 147-155. [CrossRef] 
26. Geiger, P.; Aron, R.H.; Todhunter, P. The Climate near the Ground; Rowman \& Littlefield Publishers Inc.: Lanham, MD, USA, 2009.

27. Konarska, J.; Lindberg, F.; Larsson, A.; Thorsson, S.; Holmer, B. Transmissivity of solar radiation through crowns of single urban trees-application for outdoor thermal comfort modelling. Theor. Appl. Climatol. 2014, 117, 363-376. [CrossRef]

28. Matsuoka, M.; Hayasaka, T.; Fukushima, Y.; Honda, Y. Land cover in East Asia classified using terra MODIS and DMSP OLS products. Int. J. Remote Sens. 2007, 28, 221-248. [CrossRef]

29. Akbari, H.; Rose, L.S. Characterizing the Fabric of the Urban Environment: A Case Study of Metropolitan Chicago, Illinois; Lawrence Berkeley National Laboratory Report LBNL-49275: Berkeley, CA, USA, 2001; pp. 1-64.

30. Akbari, H.; Rose, L.S. Characterizing the Fabric of the Urban Environment: A Case Study of Salt Lake City, Utah; Lawrence Berkeley National Laboratory Report LBNL- 47851: Berkeley, CA, USA, 2001; pp. 1-51.

31. Rose, L.S.; Akbari, H.; Taha, H. Characterizing the Fabric of the Urban Environment: A Case Study of Greater Houston, Texas; U.S. Environmental Protection Agency under the Urban Heat Island Pilot Project, University of California: Berkeley, CA, USA, 2003; pp. 1-64.

32. Geneletti, D.; Gorte, B.G.H. International Journal of Remote Sensing A method for object-oriented land cover classification combining Landsat TM data and aerial photographs. Int. J. Remote Sens. 2003, 24, 1273-1286. [CrossRef]

33. Guo, G.; Wu, Z.; Xiao, R.; Chen, Y. Landscape and Urban Planning Impacts of urban biophysical composition on land surface temperature in urban heat island clusters. Landsc. Urban Plan. 2015, 135, 1-10. [CrossRef]

34. Chang, C.-R.; Li, M.-H.; Chang, S.-D. A preliminary study on the local cool-island intensity of Taipei city parks. Landsc. Urban Plan. 2007, 80, 386-395. [CrossRef]

35. Kim, G.; Coseo, P. Urban Park Systems to Support Sustainability: The Role of Urban Park Systems in Hot Arid Urban Climates. Forests 2018, 9, 439. [CrossRef]

36. Solecki, W.D.; Rosenzweig, C.; Parshall, L.; Pope, G.; Clark, M.; Cox, J.; Wiencke, M. Mitigation of the heat island effect in urban New Jersey. Environ. Hazards 2005, 6, 39-49. [CrossRef]

37. Nichol, J.; Wong, M.S. Modeling urban environmental quality in a tropical city. Landsc. Urban Plan. 2005, 73, 49-58. [CrossRef]

38. Chen, X.-L.; Zhao, H.-M.; Li, P.-X.; Yin, Z.-Y. Remote sensing image-based analysis of the relationship between urban heat island and land use/cover changes. Therm. Remote Sens. Urban Areas 2006, 104, 133-146. [CrossRef]

39. Gill, S.E.; Handley, J.F.; Ennos, A.R.; Pauleit, S.; Theuray, N.; Lindley, S.J. Characterising the urban environment of UK cities and towns: A template for landscape planning. Landsc. Urban Plan. 2008, 87, 210-222. [CrossRef]

40. Gray, K.A.; Finster, M.E. The Urban Heat Island, Photochemical Smog, and Chicago: Local Features of the Problem and Solution. Available online: https://www.coolrooftoolkit.org/wp-content/uploads/2015/01/ Chicago-UHI-EPA.pdf (accessed on 1 July 2012).

41. Li, G.; Weng, Q. Measuring the quality of life in city of Indianapolis by integration of remote sensing and census data. Int. J. Remote Sens. 2007, 28, 249-267. [CrossRef]

42. Liang, B.; Weng, Q. Assessing Urban Environmental Quality Change of Indianapolis, United States, by the Remote Sensing and GIS Integration. IEEE J. Sel. Top. Appl. EARTH Obs. Remote Sens. 2011, 4, 43-55. [CrossRef]

43. Mcpherson, E.G.; Nowak, D.J.; Rowntree, R.A.; Gregory, E.; David, J.; Rowan, A. Chicago's Urban Forest Ecosystem: Results of the Chicago Urban Forest Climate Project; Gen. Tech. Rep. NE-186; US Department of Agriculture, Forest Service, Northeastern Forest Experiment Station: Radnor, PA, USA, 1994; 201p.

44. Nowak, D.J.; Greenfield, E.J. Tree and impervious cover in the United States. Landsc. Urban Plan. 2012, 107, 21-30. [CrossRef]

45. Nowak, D.J.; Rowntree, R.A.; McPherson, E.G.; Sisinni, S.M.; Kerkmann, E.R.; Stevens, J.C. Measuring and analyzing urban tree cover. Landsc. Urban Plan. 1996, 36, 49-57. [CrossRef]

46. Yuan, F.; Bauer, M.E. Comparison of impervious surface area and normalized difference vegetation index as indicators of surface urban heat island effects in Landsat imagery. Remote Sens. Environ. 2007, 106, 375-386. [CrossRef]

47. US Census Bureau. Chicago 2010 US Census Population Information. Available online: http://2010.census. gov/2010census/ (accessed on 7 January 2012).

48. USGS. Earth Explorer Web Tool. Available online: http://earthexplorer.usgs.gov/ (accessed on 7 January 2012). 
49. USGS. Elevations and Distances in the United States. Available online: https://pubs.usgs.gov/gip/70039193/ report.pdf (accessed on 1 July 2012).

50. Hayhoe, K.; Sheridan, S.; Kalkstein, L.; Greene, S. Climate change, heat waves, and mortality projections for Chicago. J. Great Lakes Res. 2010, 36, 65-73. [CrossRef]

51. Wuebbles, D.J.; Hayhoe, K.; Parzen, J. Introduction: Assessing the effects of climate change on Chicago and the Great Lakes. J. Great Lakes Res. 2010, 36, 1-6. [CrossRef]

52. Hayhoe, K.; Vandorn, J.; Croley, T.; Schlegal, N.; Wuebbles, D. Regional climate change projections for Chicago and the US Great Lakes. JGLR 2010, 36, 7-21. [CrossRef]

53. Coseo, P.; Larsen, L. Cooling the Heat Island in Compact Urban Environments: The Effectiveness of Chicago's Green Alley Program. Procedia Eng. 2015, 118, 691-710. [CrossRef]

54. Sharma, A.; Conry, P.; Fernando, H.J.S.; Hamlet, A.F.; Hellmann, J.J.; Chen, F. Green and cool roofs to mitigate urban heat island effects in the Chicago metropolitan area: evaluation with a regional climate model. Environ. Res. Lett. 2016, 11, 064004. [CrossRef]

55. McPherson, E.G.; Nowak, D.; Heisler, G.; Grimmond, S.; Souch, C.; Grant, R.; Rowntree, R. Quantifying urban forest structure, function, and value: the Chicago Urban Forest Climate Project. Urban Ecosyst. 1997, 1, 49-61. [CrossRef]

56. Attarian, J. Infrastructure for Great Cities: Illinois Sustainable Cities Symposium, standingupforillinois.org. 2008. Available online: http://www.standingupforillinois.org/pdf/green/AttarianSCS.pdf (accessed on 21 January 2008).

57. Chicago of City. Elevated Surface Temperature Maps; Chicago of City: Chicago, IL, USA, 2006.

58. Onset. HOBO Data Loggers. Available online: http://www.onsetcomp.com/ (accessed on 7 January 2012).

59. Oke, T.R. Initial guidance to obtain representative meteorological observations at urban sites. World Meteorol. Organ. 2004, 81, 51.

60. MetroWest. Weather data. 2010. Available online: http://mesowest.utah.edu/index.html (accessed on 12 December 2012).

61. Stewart, I.D.; Oke, T.R. Local Climate Zones for Urban Temperature Studies. Bull. Am. Meteorol. Soc. 2012, 93, 1879-1900. [CrossRef]

62. Unger, J.; Savic, S.; Gal, T. Modelling of the Annual Mean Urban Heat Island Pattern for Planning of Representative Urban Climate Station Network. Adv. Meteorol. 2011, 2011. [CrossRef]

63. Wicki, A.; Parlow, E.; Feigenwinter, C. Evaluation and Modeling of Urban Heat Island Intensity in Basel, Switzerland. Climate 2018, 6, 55. [CrossRef]

64. Yan, H.; Fan, S.; Guo, C.; Hu, J.; Dong, L. Quantifying the Impact of Land Cover Composition on Intra-Urban Air Temperature Variations at a Mid-Latitude City. PLoS ONE 2014, 9, e102124. [CrossRef] [PubMed]

65. O'brien, R.M.O. A Caution Regarding Rules of Thumb for Variance Inflation Factors. Qual. Quant. 2007, 41, 673-690. [CrossRef]

66. Zou, H.; Hastie, T. Regularization and variable selection via the elastic net. J. R. Stat. Soc. Ser. B Stat. Methodol. 2005, 67, 301-320. [CrossRef]

67. Huang, C.; Townshend, J.R.G. A stepwise regression tree for nonlinear approximation: Applications to estimating subpixel land cover. Int. J. Remote. Sens. 2003, 24, 75-90. [CrossRef]

68. O’Neil-dunne, J.; Macfaden, S.; Royar, A. A Versatile, Production-Oriented Approach to High-Resolution Tree-Canopy Mapping in Urban and Suburban Landscapes Using GEOBIA and Data Fusion. Remote. Sens. 2014, 6, 12837-12865. [CrossRef]

69. Zhang, Y. Evaluating the effect of 3D urban form on neighborhood land surface temperature using Google Street View and geographically weighted regression. Landsc. Ecol. 2019, 34, 681-697. [CrossRef]

70. Middel, A.; Lukasczyk, J.; Zakrzewski, S.; Arnold, M.; Maciejewski, R. Urban form and composition of street canyons: A human-centric big data and deep learning approach. Landsc. Urban Plan. 2019, 183, 122-132. [CrossRef]

(C) 2019 by the authors. Licensee MDPI, Basel, Switzerland. This article is an open access article distributed under the terms and conditions of the Creative Commons Attribution (CC BY) license (http://creativecommons.org/licenses/by/4.0/). 